\title{
Measurement of Tidal Volume during High Frequency Ventilation by Impedance Plethysmography
}

\author{
KENNETH L. SANDBERG, DANIEL P. LINDSTROM, ELIZABETH D. KRUEGER, \\ HAKAN SUNDELL, AND ROBERT B. COTTON \\ Department of Pediatrics, Vanderbilt University Medical Center, Nashville, Tennessee 37232
}

\begin{abstract}
Electrical impedance plethysmography was evaluated in lambs as a method of measuring tidal volume $\left(V_{T}\right)$. Over tidal volumes ranging from 15 to $414 \%$ of estimated dead space, and frequencies of 300 to 1000 breaths/min, correlation between $V_{\Upsilon}$ measured by the impedance technique and $V_{\mathrm{T}}$ measured by whole-body plethysmography was 0.98 . Above 600 breaths/min, the correlation between the two methods was 0.94 . Independent calibration of the impedance technique using a pneumotachograph at conventional rates of ventilation yielded absolute values of $V_{T}$ which closely corresponded to values obtained with the whole-body plethysmograph (slope = 1.05 , intercept $=1.4 \mathrm{ml}, r=0.99$ ). These results support the potential utility of impedance plethysmography in clinical applications of high frequency ventilation. (Pediatr Res 23: 253-256, 1988)
\end{abstract}

\section{Abbreviations}

HFV, high frequency ventilation

VDR, volumetric diffusion respirator

$V_{f}$, thoracic fluid volume

$\Delta V_{f}$, variation in thoracic fluid volume

$V_{g}$, thoracic gas volume

$\Delta \mathbf{V}_{\mathrm{g}}$, variation in thoracic gas volume

$V_{T}$, tidal volume

$V_{\text {TZ }}$, tidal volume by impedance method

$\mathrm{Z}_{x}$, tidal impedance

$\Delta \mathrm{Z}$, impedance variation

$\rho$, resistivity of thoracic fluid

$\mathrm{Z}_{0}$, baseline transthoracic impedance

Direct measurement of $\mathrm{V}_{\mathrm{T}}$ during $\mathrm{HFV}$ is difficult if not impossible in most clinical circumstances due to constraints resulting from limited frequency response and high gas velocity. These difficulties are compounded in newborn and premature infants because of their small size, critical dependence on a closely regulated thermal environment, and inability to cooperate.

Variations in transthoracic electrical impedance have been shown to correlate closely with $\mathrm{V}_{\mathrm{T}}$ during conventional ventilation (1). This investigation was undertaken to determine if impedance plethysmography could also be used during HFV to measure $\mathrm{V}_{\mathrm{r}}$. Inasmuch as the technique is noninvasive and

Received March 23, 1987; accepted October 27, 1987

Correspondence and reprint requests Robert B. Cotton, M.D., Department of Pediatrics, Vanderbilt University Hospital, Nashville, TN 37232.

Supported by NHLBI Pulmonary SCOR Grant HL 14214 unobtrusive, it would be well suited to meet the requirements of safe application in newborn infants.

\section{METHODS}

Four lambs weighing 4.0 to $10.2 \mathrm{~kg}$ were studied on 6 days between 1 and 7 wk after birth. During each study session, the lamb was sedated with chloralose, but spontaneous breathing was not abolished. After placement of a cuffed endotracheal tube through the mouth, the lamb was placed in a pressure-compensated, integrated flow, whole-body plethysmograph having a volume of 165 liters. The endotracheal tube extended through a sealed port in the plexiglass wall of the plethysmograph. $V_{T}$ was measured by pressure compensating the integrated pressure signal from the plethysmograph. The plethysmograph had been tuned to eliminate phasic distortion up to $20 \mathrm{~Hz}$.

Transthoracic electrical impedance was measured by a DCcoupled SAAB Respimeter operating at a frequency of $50 \mathrm{kHz}$ and a current of $0.2 \mathrm{~mA}$ peak to peak (2). A tetrapolar electrode system was used, with one pair of electrodes attached to each side of the lamb's chest wall after shaving. Each electrode had a circular silver-silver chloride surface $0.8 \mathrm{~cm}$ in diameter and each electrode pair was housed in a soft rubber casing that maintained a constant interelectrode distance of $2.25 \mathrm{~cm}$ center to center. Within each electrode pair, one electrode was used for current injection and the other was used to detect voltage drop. This type of impedance bridge minimizes the effect of resistance variations at the skin-electrode interface. The frequency response of the impedance bridge was found to be flat below $20 \mathrm{~Hz}$.

HFV was provided by a Bird VDR. The Bird VDR is a flowinterrupter type of high frequency ventilator that has a pneumatic inspiratory/expiratory valve driven by a pressure pulse generator. Its design allows spontaneous breaths to occur simultaneously with HFV. Humidification was provided by an unheated jet nebulizer.

The impedance signal, plethysmograph volume signal, and inspiratory pressure pulse were recorded simultaneously with an analog tape recorder (Vetter model D) and with a HewlettPackard 7754B chart recorder. The plethysmograph volume calibration signal was produced by repeated manual injections of $20 \mathrm{ml}$ air into the sealed plethysmograph before placement of the lamb. Calibration linearity had been previously established. The respimeter produces a $1 \mathrm{ohm}$ calibration signal, appropriate for the range of impedance fluctuations observed $(0.05-2.75$ ohm). Examples of the raw impedance and plethysmograph volume signals are shown in Figure 1.

The high frequency $V_{T}$ component of the impedance and plethysmograph volume signals was extracted from low frequency $V_{T}$ fluctuations associated with spontaneous breathing by means of a signal averaging technique carried out off-line using a DEC PDP-11/34 laboratory computer system (3). The 

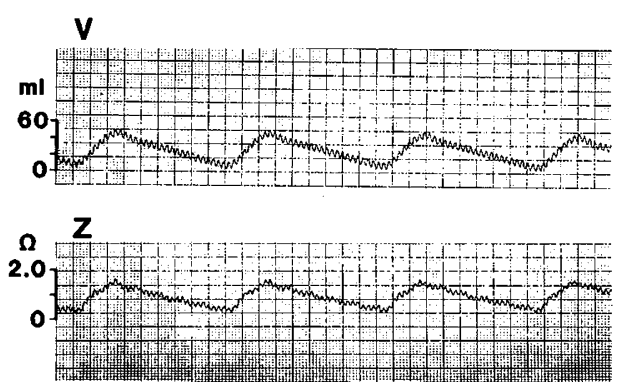

Fig. 1. Plethysmograph volume signal (top) and transthoracic impedance signal (bottom) recorded simultaneously during HFV at a rate of 900 breaths/min. The small high frequency $V_{T}$ excursions are superimposed on larger low frequency spontaneous $V_{\mathrm{T}}$ excursions.

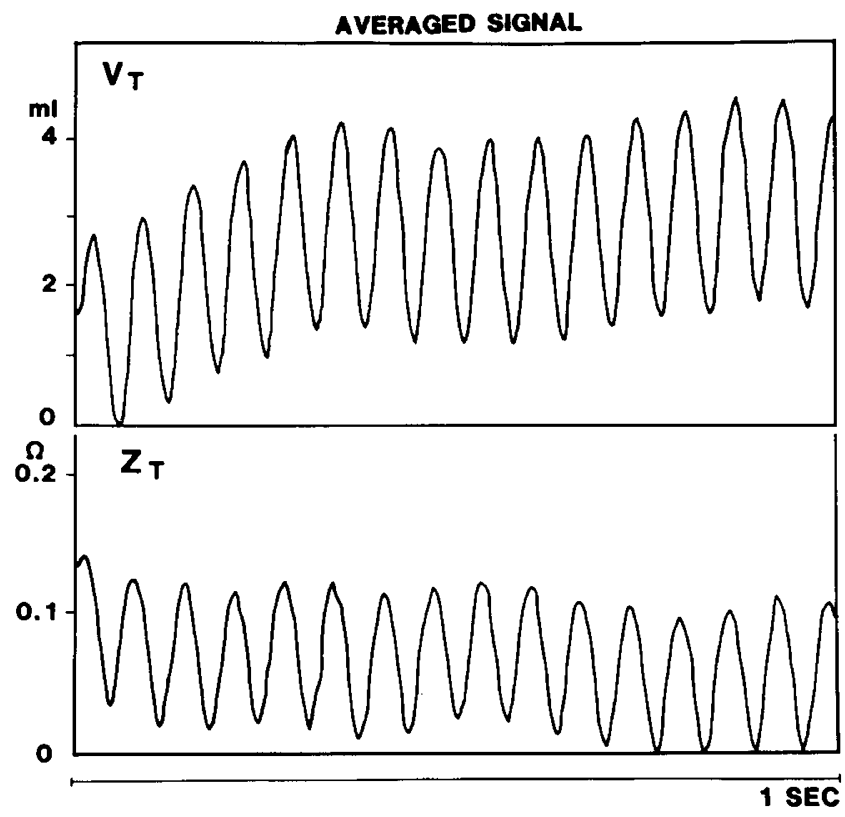

Fig. 2. Computer-averaged plethysmograph high frequency $\mathrm{V}_{\mathrm{T}}$ waveform and its corresponding impedance counterpart $\left(Z_{\mathrm{T}}\right)$.

inspiratory pressure pulse generated by the Bird VDR was used as the trigger for the signal averaging process. Episodes of impedance, volume, and respirator trigger signals were digitized at a $250 \mathrm{~Hz}$ rate. Twenty-five to fifty $1-\mathrm{s}$ windows, each centered on the trigger point, were averaged. This technique removes much of the low frequency component of the impedance signal including baseline changes, the cardiogenic impedance signal, and the random noise. Examples of the averaged plethysmograph volume waveform and the averaged impedance waveform are shown in Figure 2. High frequency $V_{T}$ for an individual study was taken as the mean of the time-averaged plethysmograph volume deflections shown in Figure 2. Similarly, the $Z_{T}$ was taken as the mean of time-averaged impedance deflections expressed in ohms. Each of the 139 studies reported below resulted in a set of computer-averaged waveforms as shown in Figure 2. Each point in Figures 3 and 4 represents one of the 139 studies.

During each day of studies, multiple $1-\mathrm{min}$ recordings were made while the lamb received high frequency ventilation. $Z_{0}$ (ohm) obtained from a 10-turn potentiometer on the SAAB respimeter used to balance the impedance bridge, was noted for each study. Frequency and $V_{T}$ were varied arbitrarily over ranges of 200 to 1087 breaths $/ \mathrm{min}$, and 2.3 to $90.2 \mathrm{ml}$, respectively. Leaks around the endotracheal tube, which were readily detected by changes in the baseline plethysmograph volume signal, were abolished by inflating the cuff. Temperature within the plethysmograph never varied more than $2^{\circ} \mathrm{C}$ during a daily session.

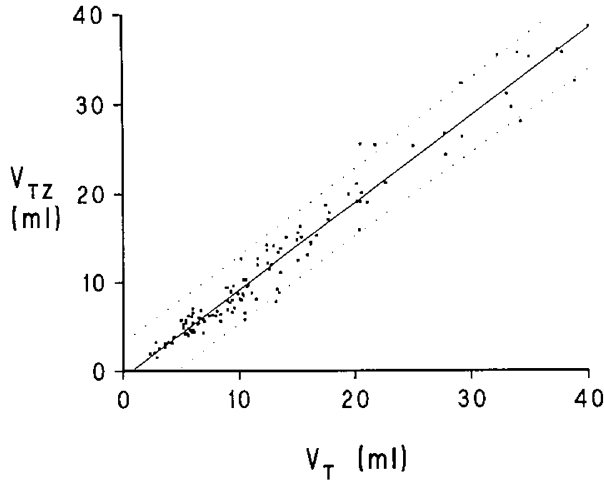

Fig. 3. Relationship between $V_{T}$ estimated by impedance plethysmography $\left(\mathrm{V}_{\mathrm{TZ}}\right)$ and $\mathrm{V}_{\Upsilon}$ measured using the whole-body plethysmograph $\left(V_{\mathrm{T}}\right)$. Results are shown for the 122 studies which were calibrated against the plethysmograph during ventilation at frequencies between 200-305 breaths $/ \mathrm{min}$. The linear regression $\left(\mathrm{V}_{\mathrm{TZ}}=0.98 \times \mathrm{V}_{\mathrm{T}}-0.71\right)$ is shown as a solid line and $95 \%$ confidence limits of $\mathrm{V}_{\mathrm{TZ}}$ are indicated by dotted lines. Calibration data pairs are not included in this figure.

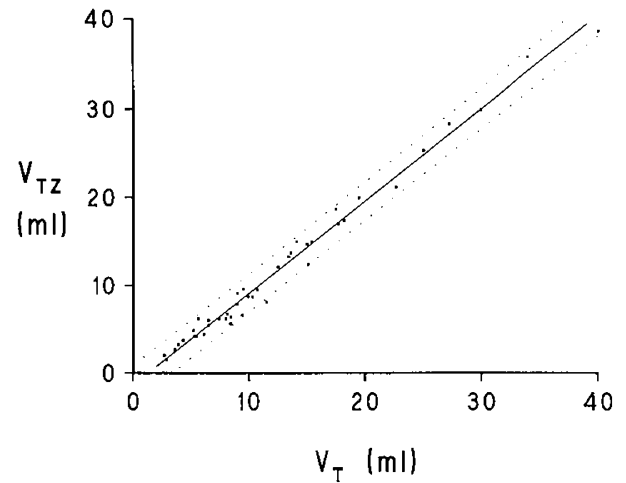

Fig. 4. Relationship between $V_{T}$ estimated by impedance plethysmography $\left(\mathrm{V}_{\mathrm{TZ}}\right)$ and $\mathrm{V}_{\mathrm{T}}$ measured using the whole-body plethysmograph $\left(V_{T}\right)$. Results are shown for the 42 studies that were calibrated using the pneumotachograph during spontaneous ventilation or during conventional mechanical ventilation at a rate of 50 breaths $/ \mathrm{min}$. The linear regression $\left(\mathrm{V}_{\mathrm{Tz}}=1.05 \times \mathrm{V}_{\mathrm{T}}-1.4\right)$ is shown by solid lines and $95 \%$ confidence limits of $\mathrm{V}_{\mathrm{TZ}}$ are indicated by dotted lines.

In two lambs, a calibration constant relating impedance to $V_{T}$ measured with a pneumotachograph was obtained, in one case during spontaneous breathing with the ventilator disconnected, and in the other case while the lamb was receiving intermittent positive pressure ventilation at a rate of 50 breaths/min provided by a babyBird infant ventilator. This segment of the study was carried out to simulate calibration of the impedance signal within the constraints of a clinical setting involving premature and other newborn infants requiring mechanical ventilation. $V_{\mathrm{T}}$ during expiration was measured by electrically integrating expiratory flow using a Hewlett-Packard $8815 \mathrm{~A}$ respiratory flow integrator. Flow was measured using a Number 0 Fleisch pneumotachograph and a Hewlett-Packard 47304A differential pressure transducer and amplifier. Simultaneous measurements of $V_{\Upsilon}$ by the plethysmograph confirmed the accuracy of $V_{T}$ measured from the pneumotachograph signal. The calibration constant was determined by dividing $\mathrm{V}_{\mathrm{T}}$ by the magnitude of the corresponding impedance deflection and expressed in $\mathrm{ml} / \mathrm{ohm}$.

\section{RESULTS}

One hundred thirty-nine studies were recorded during study sessions occurring on 6 different days. Duration of time between the first and last study of a study session ranged from 83 to 192 
min. One to four studies of each session obtained at the lowest frequencies (200-305 breaths/min) were used to establish a within-session calibration of impedarce versus volume in order to express $Z_{\mathrm{T}}(\mathrm{ohm})$ as $\mathrm{V}_{\mathrm{TZ}}(\mathrm{ml})$. These calibration studies were excluded in the analysis of results pooled from all six study sessions, leaving 122 studies for consideration.

Comparison of impedance method with plethysmography. Table 1 contains estimated linear regression parameters between $\mathrm{V}_{\mathrm{TZ}}$ and $\mathrm{V}_{\mathrm{T}}$ for the six individual study sessions and for data pooled from all study sessions. All slopes were very close to unity and all except one study session yielded intercepts less than 1.0 $\mathrm{ml}$ from zero. Deviation of impedance-derived $V_{T}$ from $V_{T}$ measured with the plethysmograph was expressed as the ratio $\mathrm{V}_{\mathrm{TZ}} / \mathrm{V}_{\mathrm{T}}$. Analysis of variance of this ratio between the six study sessions revealed no significant difference in performance of the impedance technique from day to day and animal to animal $\left(\mathrm{F}_{5}\right.$, $\left.{ }_{116}=1.87 ; p>0.10\right)$. Therefore, the results from all six sessions were considered as a group for subsequent analysis.

The relationship between $V_{T Z}$ and $V_{T}$ is shown in Figure 3. Linear regression yielded $\mathrm{V}_{\mathrm{TZ}}=0.98 \times \mathrm{V}_{\mathrm{T}}-0.71, r=0.98$. Stepwise multiple linear regression was carried out to determine if the $V_{\mathrm{TZ}} / \mathrm{V}_{\mathrm{T}}$ ratio depended on frequency, $\mathrm{V}_{\mathrm{T}}$ as a percentage of dead space (assumed to be $2.0 \mathrm{ml} / \mathrm{kg}$ ), $\mathrm{Z}_{0}$, or elapsed time in minutes after the first study of a session. $F$ ratios for $V_{T}$ as a percent of dead space, $\mathrm{Z}_{0}$, and elapsed time as contributors to the variance in $\mathrm{V}_{\mathrm{TZ}} / \mathrm{V}_{\mathrm{T}}$ were $1.5,0.5$, and 1.4 , respectively, all nonsignificant with 1 and 117 degrees of freedom. $V_{\mathrm{TZ}} / \mathrm{V}_{\mathrm{T}}$ was significantly dependent on frequency $\left(\mathrm{F}_{1,117}=13.2, p<0.001\right)$.

Within the 122 studies, $\mathrm{V}_{\mathrm{T}}$ was varied from 2.7 to $40.0 \mathrm{ml}$. $\mathrm{V}_{\mathrm{T}}$ expressed as percentage of an assumed dead space of $2.0 \mathrm{ml} / \mathrm{kg}$ ranged from 15 to $414 \%$. The distribution of $\mathrm{V}_{\mathrm{T}}$ as a percentage of dead space is given in Table 2 .

Calibration of impedance method with pneumotachography. Forty-two studies from two lambs were obtained during study sessions which also included calibration of $Z_{T}$ against $V_{T}$ measured with a pneumotachograph during ventilation at conventional rates. Calibration constants for the two lambs were 39.4 and $53.6 \mathrm{ml} / \mathrm{ohm}$. Frequencies ranged between 300 and 900 breaths/min and $\mathrm{V}_{\mathrm{T}}$ was varied between 20 and $220 \%$ of dead space. The distribution of $V_{T}$ within this subset of studies is given in Table 1. The relation between $V_{\Upsilon Z}$ derived using the calibration constant obtained during conventional rate ventilation and $\mathrm{V}_{\mathrm{T}}$ obtained from the plethysmograph is shown in Figure 4. Linear regression yielded $\mathrm{V}_{\mathrm{TZ}}=1.05 \times \mathrm{V}_{\mathrm{T}}-1.4, r=0.99 . \mathrm{V}_{\mathrm{TZ}}$

Table 1. Regressions of individual studies

\begin{tabular}{ccccccc}
\hline Study & Lamb & Slope & Intercept & $r$ & S $^{*}$ & $n$ \\
\hline 1 & A & 0.95 & -0.43 & 0.966 & 2.53 & 26 \\
2 & B & 0.97 & -0.62 & 0.986 & 1.61 & 21 \\
3 & C & 0.97 & -0.96 & 0.980 & 1.12 & 18 \\
4 & C & 0.93 & -0.80 & 0.989 & 1.45 & 18 \\
5 & D & 1.07 & -0.76 & 0.979 & 1.76 & 19 \\
6 & D & 1.05 & -1.18 & 0.996 & 0.91 & 20 \\
$1-6$ & All & 0.982 & -0.70 & 0.980 & 1.79 & 122
\end{tabular}

${ }^{*} \mathrm{~S}_{\mathrm{Y}}$ is the $\mathrm{SE}$ of the estimate of $\mathrm{V}_{\mathrm{TZ}}$.

Table 2. Distribution of $V_{T}$ as $\%$ of $V_{D}$

\begin{tabular}{cccccc}
\hline & \multicolumn{2}{c}{$\begin{array}{c}\text { All studies } \\
(n=122)\end{array}$} & & \multicolumn{2}{c}{$\begin{array}{c}\text { Calibrated } \\
\text { Studies } \\
(n=42)\end{array}$} \\
\cline { 2 - 3 } \cline { 5 - 6 }$\% \mathrm{~V}_{\mathrm{D}}$ & $n$ & $\%$ & & $n$ & $\%$ \\
\hline 550 & 42 & 35 & & 20 & 48 \\
$50-100$ & 48 & 39 & & 13 & 31 \\
$100-150$ & 17 & 14 & & 5 & 12 \\
$>150$ & 15 & 12 & & 4 & 9 \\
\hline
\end{tabular}

differed from $\mathrm{V}_{\Upsilon}$ by no more than $20 \%$ in 31 (74\%), and by no more than $25 \%$ in $36(86 \%)$ of these 42 studies.

Again, step-wise multiple linear regression revealed no significant dependence of $\mathrm{V}_{\mathrm{TZ}} / \mathrm{V}_{\mathrm{T}}$ on $\mathrm{V}_{\mathrm{T}}$ as percentage of dead space $\left(F_{1,37}=0.3\right)$ or on elapsed time after the first study of a session $\left(F_{1,37}=0.1\right)$. Within this subset of 42 studies, $V_{\mathrm{TZ}} / \mathrm{V}_{\mathrm{T}}$ was significantly dependent on $\mathrm{Z}_{0}\left(\mathrm{~F}_{1,37}=4.2, p<0.05\right)$ and on frequency $\left(\mathrm{F}_{1,37}=63.8, p<0.001\right)$.

\section{DISCUSSION}

The results of this study validate the use of impedance plethysmography to measure $\mathrm{V}_{\mathrm{T}}$ during HFV of infant lambs. Even though the response is somewhat dependent on frequency, it appears that the relationship between $V_{T}$ and $Z_{T}$ is sufficiently linear so that calibration during low rate conventional ventilation can be applied during HFV with acceptable results for most applications, especially when circumstances preclude the use of whole-body plethysmography.

This investigation of impedance plethysmography was motivated by the limitations of existing methods of measuring tidal volume in newborn infants receiving HFV. Weisberger et al. (4) have demonstrated that $\mathrm{V}_{\mathrm{r}}$ during high frequency jet ventilation can be measured with a pneumotachograph by integrating only the expiratory phase of a ventilatory cycle. However, we are not aware of methods suitable for critically ill newborn infants that can be applied at frequencies above $8-10 \mathrm{~Hz}$ with tidal volumes ranging well below dead space.

Transthoracic electrical impedance is determined by the relative amounts of gas (nonconductor) and fluid (conductor) in the thorax. With each inspiration, there is an increase in the air:fluid ratio within the thorax, resulting in a corresponding increase in transthoracic impedance. Conversely, during expiration, transthoracic impedance decreases. Olsson et al. (2) have proposed a model that describes the relationship between transthoracic impedance and thoracic gas and fluid volumes:

$$
\begin{aligned}
\mathrm{Z}_{0} & =(\rho / 2 \pi) \times\left(1+\left(\mathrm{V}_{\mathrm{g}} / \mathrm{V}_{\mathrm{f}}\right)\right) \\
\frac{\Delta \mathrm{Z}}{\mathrm{Z}_{0}} & =\frac{\mathrm{V}_{\mathrm{g}}}{\mathrm{V}_{\mathrm{g}}+\mathrm{V}_{\mathrm{f}}} \times\left(\frac{\Delta \mathrm{V}_{\mathrm{g}}}{\mathrm{V}_{\mathrm{g}}}-\frac{\Delta \mathrm{V}}{\mathrm{V}_{\mathrm{f}}}\right)
\end{aligned}
$$

The statistically significant dependence of $\mathrm{V}_{\mathrm{TZ}} / \mathrm{V}_{\mathrm{T}}$ on $\mathrm{Z}_{0}$ observed in the subset of independently calibrated studies is consistent with equation 2 which predicts that an increase in $Z_{0}$ will result in an increase in $Z_{\Upsilon}$ when $V_{T}$ is held constant. Multiple linear regression of $V_{T Z}$ as a function of $Z_{0}$, frequency, and $V_{T}$ revealed that the magnitude of effect of $Z_{0}$ on $V_{T Z}$ was approximately $0.06 \mathrm{ml} / \mathrm{ohm}$. The importance of this effect in introducing error in the estimation of $V_{T}$ by $V_{T Z}$ will be minor under most circumstances. As long as $Z_{0}$ does not vary more than 10 ohms during a study session, recalibration is probably unnecessary.

$\mathrm{V}_{\mathrm{TZ}} / \mathrm{V}_{\mathrm{X}}$ was observed to be dependent on frequency in the larger group of 122 studies as well as in the subset of 42 studies with independent calibration. The correlation between $V_{\mathrm{TZ}} / \mathrm{V}_{\mathrm{T}}$ and frequency was inverse, indicating that $V_{T Z}$ would underestimate $V_{T}$ at higher frequencies. The importance of this frequency dependence was examined by considering separately studies made above and below 600 breaths/min (see Table 3). Above 600 breaths/min, $V_{T Z}$ underestimated $V_{T}$ measured by the plethysmograph, but by only $17 \%$. This magnitude of underestimation will not seriously compromise the use of the impedance technique for most clinical applications.

Table 3. Frequency dependence of $V_{T Z}$

\begin{tabular}{ccccc}
\hline Frequency & $n$ & $\mathrm{~V}_{\mathrm{T}}(\mathrm{ml})$ & $\mathrm{SD}(\mathrm{ml})$ & $\mathrm{V}_{\mathrm{TZ}} / \mathrm{V}_{\mathrm{T}}$ \\
\hline$<10 \mathrm{~Hz}$ & 52 & 19.1 & 10.1 & 1.00 \\
$\geq 10 \mathrm{~Hz}$ & 70 & 8.6 & 4.1 & 0.83 \\
\hline
\end{tabular}


The origin of the influence of frequency on the relationship between $V_{T Z}$ and $V_{T}$ is not established by these studies. One explanation is that the distribution of a $V_{T}$ within the airways is frequency dependent, such that the gas volume increment within that part of the lungs between the electrodes is less at higher frequencies. This explanation is consistent with the observation by other investigators $(5,6)$ that distribution of ventilation during $\mathrm{HFV}$ varies with frequency. Another explanation involves the possibility that $Z_{T}$ is influenced by variations in pulmonary blood volume accompanying each high frequency inspiration. As predicted by Olsson's equation 2 , an increment in pulmonary blood volume $\left(\Delta \mathrm{V}_{\mathrm{f}}\right)$ will result in a negative impedance deflection. If either the magnitude or regional distribution of fluctuations in pulmonary blood volume accompanying high frequency inspirations were frequency dependent, the relationship between $V_{T Z}$ and $V_{T}$ would also be influenced by frequency.

$\mathrm{V}_{\mathrm{TZ}} / \mathrm{V}_{\mathrm{T}}$ was not significantly dependent on either $\mathrm{V}_{\mathrm{T}}$ or elapsed time after the first study of a session. This technique appears reliable over a wide range of $V_{T}$. Its sensitivity for estimating $V_{T}$ as small as $15 \%$ of dead space is the result of the signal averaging process that removes variations in the impedance signal not correlated with HFV. The absence of any significant drift in $\mathrm{V}_{\mathrm{TZ}} /$ $\mathrm{V}_{\mathrm{T}}$ during studies of up to $3 \mathrm{~h}$ indicates the stability of the electrode-skin interface.

The results of this investigation establish impedance plethysmography as a potentially valuable tool in clinical applications of HFV, particularly among newborn infants. Clinical studies and intensive care monitoring of this group of patients are especially dependent on the availability of measuring techniques which are noninvasive and unobtrusive, both features of impedance plethysmography.

These studies provide convincing evidence that impedance plethysmography is a valid technique to measure $V_{T}$ during HFV delivered by a flow interrupter to lambs with normal lungs. Additional studies are needed to confirm the reliability of the technique with high frequency oscillatory ventilation and in the presence of lung disease.

Acknowledgment. VDR was provided by Dr. Forrest M. Bird, Bird Space Technology, Sandpoint, ID.

\section{REFERENCES}

1. Riha M, Olsson T, Hjalmarson O, Cotton, R 1976 Transthoracic impedance variations used as volume variables for the measurement of pulmonary ventilation and mechanics in newborn infants. Technical Report 3:76 Research Laboratory of Medical Electronics, Chalmers University of Technology, Gothenburg, Sweden

2. Olsson T, Daily W, Victorin L 1970 Transthoracic impedance: I. Theoretical considerations and technical approach. Acta Paediatr Scand [Suppl] 207:1527

3. Cotton RB, Lindstrom DP, Olsson T, Riha M, Graham TP, Selstam U, Catterton WZ 1980 Impedance cardiographic assessment of symptomatic patent ductus arteriosus. J Pediatr 96:711-715

4. Weisberger SA, Carlo WA, Fouke JM, Chatburn RL, Tillander T, Martin RJ 1986 Measurement of tidal volume during high-frequency jet ventilation. Pediatr Res 20:45-48

5. Brusasco V, Knopp TJ, Schmid ER, Rehder K 1982 Ventilation-perfusion relationship during high-frequency ventilation. J Appl Physiol: 52:683-689

6. Allen JL, Frantz ID, Fredberg J 1985 Regional alveolar pressure during periodic flow: dual manifestations of gas inertia. J Clin Invest 76:620-629

\section{Announcement 1988 Meeting of the European Society for Pediatric Research}

The meeting will take place June 19-22, 1988 at the University Center, Blindern, Oslo, Norway. It will include plenary sessions devoted to neonatology, cardiology, and cellular growth factors. Oganized symposia topics will include: oxygen toxicity and free radicals, Reye's syndrome, surfactant, extracorporeal membrane oxygenation, high frequency ventilation, mineral metabolism, prevention and management of pain, cellular growth factors, and fetal echocardiography.

Official language for the meeting will be English.

Deadline for abstracts: February 15, 1988; deadline for early registration: March 15, 1988.

For more information contact the President: Professor Sverre Halvorsen, Department of Pediatrics, Ulleval Hospital, 0407 Oslo 4, Norway, Phone: (47 2) 4618 70. or Organizing Secretariat, ESPR 1988, Congress Service, PO Box 55, Blindern, 0313 Oslo 3, Norway. 